\title{
Clinical Characteristics and Outcomes of Critically Ill Neurological Patients with COVID-19 Infection in Neuro-intensive Care Unit: A Retrospective Study
}

Rohini M Surve ${ }^{1} \odot$, Rajeeb K Mishra ${ }^{2}$, Soumya R Malla ${ }^{3} \odot$, Sriganesh Kamath ${ }^{4} \odot$, Dhritiman R Chakrabarti $^{5}{ }^{\circ}$, Karthik Kulanthaivelu ${ }^{6}{ }^{\circ}$, Mahendranath Musunuru ${ }^{7}$

\begin{abstract}
Background: There are insufficient data about clinical outcomes in critically ill neurological patients with concomitant coronavirus disease (COVID-19). This study describes the clinical characteristics, predictors of mortality, and clinical outcomes in COVID-19-positive neurological patients managed in a dedicated COVID-19 neurointensive care unit (CNICU).

Methods: This single-center, retrospective cohort study was conducted in critically ill neurological and neurosurgical patients with concomitant COVID-19 infection admitted to the CNICU at the National Institute of Mental Health and Neurosciences (NIMHANS), Bengaluru, from July to November 2020. Patients' demographic, clinical, laboratory, imaging, treatment, and outcome data were retrieved from the manual and electronic medical records. Predictors of mortality and neurological outcome were identified using logistic regression.

Results: During the study period, 50 COVID-19-positive neurological patients were admitted to the CNICU. Six patients were excluded from the analysis as they were managed in the CNICU for $<24$ hours. A poor outcome, defined as death or motor Glasgow Coma Scale $<5$ at hospital discharge, was observed in 34 of 44 patients (77.27\%) with inhospital mortality in 26 of 44 patients (59\%). Worst modified sequential organ failure assessment (MSOFA) score, lactate dehydrogenase maximum levels $\left(\mathrm{LDH}_{\max }\right)$, and lymphocyte count were predictors of inhospital mortality with an odds ratio (OR) of $1.88,1.01$, and 0.87 , respectively, whereas worst MSOFA and $\mathrm{LDH}_{\max }$ levels were predictors for poor neurological outcome with OR of 1.99 and 1.01 , respectively.

Conclusions: Mortality is high in neurological patients with concomitant COVID-19 infection. Elevated inflammatory markers of COVID-19 suggest the role of systemic inflammation on clinical outcomes. Predictors of mortality and poor outcome were higher MSOFA score and elevated LDH levels. Additionally, lymphopenia was associated with mortality.

Keywords: COVID-19, Mortality, Neurocritical care, Neurological functional outcome, Predictors of outcome.

Indian Journal of Critical Care Medicine (2021): 10.5005/jp-journals-10071-23989
\end{abstract}

\section{HIGHLIGHTS}

- Information on clinical characteristics and predictors of poor outcome in neuro-critically ill COVID-19 patients is lacking

- The first study from India tried to explore the same in the neurocritically ill COVID-19 patients requiring mechanical ventilation

- Modified sequential organ failure assessment (MSOFA) score was a good predictor of poor outcome

- MSOFA is simpler to calculate as compared to SOFA score

- Other identified predictors of poor outcome were the inflammatory marker, like LDH and lymphopenia

\section{INTRODUCTION}

The severe acute respiratory syndrome coronavirus 2 (SARSCov-2) causing the coronavirus disease 2019 (COVID-19) is a highly infectious virus primarily affecting the respiratory system. ${ }^{1}$ Over the last several months, it has been observed that COVID-19 infection can also involve extrapulmonary systems including neurological involvement. ${ }^{2}$ The common COVID-19 related neurological presentations include headache, anosmia, dysgeusia, and myalgia, while the rare but severe manifestations reported are impaired consciousness, cerebrovascular events, movement disorder, encephalitis, and peripheral neuropathies. ${ }^{3-6}$ The mechanism involved in the COVID-19
$1,2,4,5,7$ Department of Neuroanesthesia and Neurocritical Care, National Institute of Mental Health and Neurosciences, Bengaluru, Karnataka, India

${ }^{3,6}$ Department of Neuroimaging and Interventional Radiology, National Institute of Mental Health and Neurosciences, Bengaluru, Karnataka, India

Corresponding Author: Rohini M Surve, Department of Neuroanesthesia and Neurocritical Care, National Institute of Mental Health and Neurosciences, Bengaluru, Karnataka, India, Phone: +91 9480829840, e-mail: rohinigondhule@gmail.com

How to cite this article: Surve RM, Mishra RK, Malla SR, Kamath S, Chakrabarti DR, Kulanthaivelu K, et al. Clinical Characteristics and Outcomes of Critically III Neurological Patients with COVID-19 Infection in Neuro-intensive Care Unit: A Retrospective Study. Indian J Crit Care Med 2021;25(10):1126-1132.

Source of support: Nil

Conflict of interest: None

associated neurological manifestations is still not clear, and direct corroborative evidence is lacking at present. The proposed mechanism of COVID-19 neurological manifestations includes a hematogenous spread of the virus or retrograde neuro-invasion through the olfactory bulb by binding to the 
angiotensin-converting enzyme 2 (ACE-2) receptors that are widely present in the central nervous system, ${ }^{7,8}$ whereas other indirect mechanisms could be attributed to the COVID-19 related immune-mediated effects/cytokine storm, coagulation abnormalities, and systemic hypoxia. ${ }^{8}$ The risk of neurological involvement ${ }^{5}$ as well as the severity of neurological manifestations are likely to be more in the elderly and those with severe COVID19 infection and associated comorbidities. ${ }^{3,9}$ The concomitant presence of severe neurological illness and COVID-19 is likely to render these patients more vulnerable to adverse outcomes.

The literature pertaining to clinical characteristics and predictors of poor outcomes in critically ill COVID-19 patients is accumulating, which is helpful in the understanding of this disease and its management. However, similar information lacks in critically ill neurological and neurosurgical patients with concomitant COVID-19 infection. Further, currently, there are no data from Indian population to inform the impact of COVID-19 infection in critically ill neurological patients.

The objectives of this study were to examine the clinical characteristics of critically ill neurological patients with COVID-19 infection managed in a dedicated COVID-19 neuro-intensive care unit (CNICU) and to identify the potential predictors of mortality and poor neurological outcome.

\section{Methods}

\section{Study Design and Participants}

This retrospective study was conducted at a tertiary care neurosciences center after approval from the institute's ethics committee [NIMHANS/IEC (BS and NS DIV.)/2020-2021 dated December 17, 2020]. This center was not dedicated to the management of the COVID-19 patients. However, neurological patients diagnosed with COVID-19 at admission or during the course of their management in the hospital were managed in the dedicated COVID-19 neuro-ward or CNICU till their neurological problems were addressed. Later these patients were either discharged or were referred to the COVID-19 designated hospitals depending on their neurological condition and COVID-19 status. In this study, we recruited all the critically ill neurological patients with associated COVID-19 infection (confirmed by reverse transcription-polymerase chain reaction testing) admitted to the CNICU and requiring mechanical ventilation (MV) from July 2020 to November 2020.

\section{Data Collection}

The data of the recruited patients with regard to their demographic characteristics and clinical, laboratory, imaging, treatment, and outcome details were collected from the manual and electronic records. We also collected data about diagnosis, Glasgow Coma Scale score (GCS) and motor component of GCS score (M-GCS) at admission and discharge, time of COVID-19 diagnosis (at admission or during hospital stay), desaturation [peripheral oxygen saturation $\left(\mathrm{SpO}_{2}\right)<95 \%$ despite administration of supplemental oxygen or $\mathrm{MV}$ ] of at least an hour duration any time during the hospital stay including in the CNICU, and requirement of inotropes.

\section{Chest Imaging}

Chest X-ray (CXR) and/or high-resolution computed tomography (HRCT) findings at the time of COVID-19 diagnosis and the worst CXR/HRCT findings during the CNICU admission were reviewed to quantify the extent of COVID-19 related pulmonary involvement. CXR-based Brixia score (0-18 points) with a cutoff of 8 and HRCT- based severity score (0-40 points) with a cutoff of 19.5 were used to identify severe COVID-19 infection. ${ }^{10,11}$ As HRCT was not available in all the patients, severe lung involvement was considered based on the available worst score either on CXR or HRCT. The radiologist who scored the imaging findings was not aware of the patient's clinical status.

\section{Laboratory Markers}

Biomarkers of inflammation in COVID-19 patients, such as C-reactive protein (CRP), lactate dehydrogenase (LDH), ferritin, D-dimer, and procalcitonin, were performed at the discretion of the intensivist. These details were collected when available. The levels of inflammatory markers at admission to the CNICU and their maximum (max) values during the CNICU stay were retrieved for analysis.

\section{Modified SOFA}

For assessing organ dysfunction, we used the modified sequential organ failure assessment (MSOFA) score that predicts mortality as accurately as SOFA score and is easier to implement in resourceconstrained settings. ${ }^{12}$ The MSOFA scores at admission and worst scores during the CNICU stay were collected for analysis.

\section{Outcomes}

The durations of MV, ICU stay and hospital stay, inhospital mortality, and GCS and M-GCS at hospital discharge were studied. We dichotomized the discharge outcome based on (1) survivors vs nonsurvivors and (2) poor outcome (mortality or M-GCS $<5$ at hospital discharge) vs good outcome (M-GCS $\geq 5$ at hospital discharge).

\section{Statistical Analysis}

No formal sample size was estimated as this was an exploratory study for a rapidly emerging disease condition. Data were collated offline on Microsoft Excel version 2007 spreadsheet and analyzed using $R$ version 3.5.3. Interval scale and ordinal data were described using median and interquartile range (IQR). Nominal variables were described as frequency and percentages. Association with mortality and neurological outcome for pertinent variables was conducted using binary logistic regression. Due to the small sample size, excessive parameter correlation between significant variables, and missing data in some variables, multiple regression was not conducted. A $p<0.05$ was considered statistically significant. Results of regression models are presented as odds ratios (OR) with their 95\% confidence intervals $(\mathrm{Cl})$.

\section{Results}

During the study period, 50 patients were admitted to the CNICU, of which four were for overnight observation following intracranial surgery and did not require $\mathrm{MV}$ and two patients who required $M V$ were transferred to another hospital within 24 hours of admission. Thus, after the exclusion of these six patients, data from the remaining 44 patients were analyzed. The descriptors of demographic, clinical, laboratory and therapy-related details are presented in Table 1. The median age (IQR) of our cohort was 46 years (36.75-60) with 30 males (68.2\%). Cerebrovascular pathologies, which included acute ischemic stroke (AIS), intracerebral hemorrhage $(\mathrm{ICH})$, cerebral venous thrombosis (CVT), and aneurysmal subarachnoid hemorrhage (aSAH), were the most frequent neurological diagnosis requiring management in the CNICU (15/44; 34\%) followed by traumatic brain injury (TBI) (13/44; 
Table 1: Descriptive variables of neurological patients with COVID-19 in $\mathrm{CNICU}(N=44)$

\begin{tabular}{|c|c|}
\hline Variables & $\begin{array}{l}\text { Values [median } \\
(I Q R) \text { or } n(\%) \text { ] }\end{array}$ \\
\hline \multicolumn{2}{|l|}{ Demographic and clinical variables } \\
\hline $\begin{array}{l}\text { Age (years) } \\
\text { Male } \\
\text { COVID-19 positivity at admission } \\
\text { Presence of comorbidities }\end{array}$ & $\begin{array}{l}46(36.75-60) \\
30(68.2 \%) \\
33(75 \%) \\
27(54.1 \%)\end{array}$ \\
\hline $\begin{array}{l}\text { Neurological diagnoses } \\
\text {-Neurovascular pathology } \\
\text {-Traumatic brain injury } \\
\text {-Brain tumor } \\
\text {-Others }\end{array}$ & $\begin{array}{r}15(34.1 \%) \\
13(29.5 \%) \\
9(20.5 \%) \\
7(15.9 \%)\end{array}$ \\
\hline $\begin{array}{l}\text { M-GCS at hospital admission } \\
\text { M-GCS at CNICU admission } \\
\text { M-GCS at hospital discharge }\end{array}$ & $\begin{aligned} & 5(5-6) \\
5 & (3-6) \\
5.5 & (1.25-6)\end{aligned}$ \\
\hline $\begin{array}{l}\text { MSOFA at CNICU admission } \\
\text { Worst MSOFA in the CNICU } \\
\text { Day of worst MSOFA } \\
\text { Desaturation }\left(\mathrm{SpO}_{2}<95 \% \text { ) on } \mathrm{O}_{2}\right. \\
\text { therapy (mask or } \mathrm{MV} \text { ) } \\
\text { Inotropes required in the } \mathrm{CNICU}\end{array}$ & $\begin{array}{c}6(5-9) \\
9(7-11) \\
1.5(1-6.25) \\
\\
24(54.5 \%) \\
35(79.5 \%)\end{array}$ \\
\hline \multicolumn{2}{|l|}{ Laboratory and imaging variables } \\
\hline $\begin{array}{l}\text { Laboratory parameters (normal range) } \\
\text { TLC } \times 1000 / \mathrm{uL}(4-11 \times 1000 / \mathrm{uL}) \\
\text { Lymphocyte }(\%) \text { at CNICU admission } \\
\text { (20-40\%) } \\
\text { Thrombocytopenia }(<100 \times 1000 / \mathrm{uL}) \\
\mathrm{LDH}_{\text {max }^{\prime}}(135-225 \mathrm{U} / \mathrm{L})(n=26) \\
\mathrm{CRP}_{\text {max }^{\prime}}(0-10 \mathrm{mg} / \mathrm{L})(n=23) \\
\text { Ferritin } \\
\mathrm{D}_{\max }(30-250 \mathrm{ug} / \mathrm{L})(n=22) \\
\text { Procalcitonin }(<0.5 \mathrm{ng} / \mathrm{mL})(n=41) \\
\text { Severe lung involvement on imaging }^{\prime}(<500 \mathrm{ng} \mathrm{FEU} / \mathrm{mL})(n=16)\end{array}$ & $\begin{array}{c}13(9.95-16.13) \\
9.1(5.90-12.33) \\
16(36.4 \%) \\
525(373.75-595.25) \\
96(53.50-229.50) \\
1330.5(437-2000) \\
4604(2324.25-8070.50) \\
1.06(0.17-2.88) \\
17(39.5 \%)\end{array}$ \\
\hline \multicolumn{2}{|l|}{ Treatment details } \\
\hline $\begin{array}{l}\text { Steroids ( } n=43) \text { received } \\
\text { Anticoagulants }(n=43) \text { received } \\
\text { Antivirals }(n=42) \text { received }\end{array}$ & $\begin{array}{l}34(79 \%) \\
30(69.8 \%) \\
15(35.7 \%)\end{array}$ \\
\hline \multicolumn{2}{|l|}{ CNICU and hospital outcome } \\
\hline $\begin{array}{l}\text { MV days } \\
\text { CNICU stay } \\
\text { Hospital stay } \\
\text { Mortality } \\
\text { Poor neurological outcome }\end{array}$ & $\begin{array}{l}17.5(4.75-26.25) \\
18.5(8.75-33.5) \\
27(11.5-47.5) \\
26(59.1 \%) \\
34(76.3 \%)\end{array}$ \\
\hline
\end{tabular}

COVID-19, coronavirus disease 2019; CNICU, COVID-19 neuro-intensive care unit; M-GCS, motor Glasgow coma scale; MSOFA, modified sequential organ failure assessment; $\mathrm{SpO}_{2}$, peripheral oxygen saturation; $\mathrm{O}_{2}$, oxygen; $\mathrm{TLC}$, total leukocyte count; $\mathrm{LDH}_{\text {max }}$ lactate dehydrogenase maximum levels; $\mathrm{CRP}_{\max }$ C-reactive protein maximum levels; Ferritin $_{\text {max }^{\prime}}$ ferritin maximum levels; D-dimer ${ }_{\max }$, D-dimer maximum levels; MV, mechanical ventilation

$29.5 \%)$, brain tumors $(9 / 44 ; 20.5 \%)$, and other neurological disorders, such as encephalitis and Guillain-Barre syndrome (7/44; 15.9\%). Of the 44 patients, 33 (75\%) were COVID-19 positive at admission and the remaining 11 (25\%) turned positive during their hospital stay.

Severe lung involvement on chest imaging was observed in 17 of 43 (39.5\%) patients. All the four inflammatory markers (CRP, LDH, ferritin, and D-dimer) were available in 13 patients. Among the 44 patients, $\mathrm{CRP}_{\text {max }}, \mathrm{LDH}_{\text {max }}$ Ferritin max and D-dimer max $_{\text {mevels were }}$ available in $23,26,22$, and 16 patients. Inflammatory markers were observed to be elevated above the higher normal levels in 21 of 23 (91.3\%), 25 of $26(96 \%), 19$ of 22 (86.4\%), and 16 of 16 (100\%) patients for CRP, LDH, ferritin, and D-dimer, respectively. Lymphocytes percentage was found to be $9.1(5.9-12.3)$ as compared to the normal range of 20 to $40 \%$.

The median MSOFA score at admission to the CNICU was 6 (5-9). The worst MSOFA score was 9 (7-11) and was observed at 1.5 (1-6.25) days of CNICU admission. Majority of the patients required inotropic/vasopressor support (75.9\%) and desaturation $\left(\mathrm{SpO}_{2}\right.$ $<95 \%)$, despite oxygen therapy was observed in 24 (54.5\%) patients.

All patients received standard treatment as per the need of specific neurological diagnosis and the advisory on neurocritical care practice during the COVID-19 pandemic provided by the Neurocritical Care Society of India. ${ }^{13}$ Out of 43 patients, 34 (79\%) patients received steroids (dexamethasone) and 30 (69.8\%) received anticoagulants for COVID-19 management. Unfractionated heparin (UFH) was administered to 21 (70\%) patients and low-molecularweight heparin (LMWH) to $9(30 \%)$ patients. Fifteen patients received antiviral treatment for the management of COVID-19 infection of which nine (60\%) got remdesivir and three $(20 \%)$ got favipiravir, whereas three (20\%) patients received both. All patients received vitamin $C$ and $D$, and zinc supplements.

The median (IQR) days of MV, ICU, and hospital stay were 17.5 (4.75-26.25), 18.5 (8.75-33.5), and 27 (11.5-47.5) days, respectively. A poor outcome (mortality or M-GCS $<5$ at hospital discharge) was observed in 34 of 44 (77.3\%) patients while inhospital mortality was 26 of 44 (59\%).

Pertinent variables for modeling outcomes were selected based on clinical relevance. Descriptors of the same, grouped by survivor vs non-survivors and good vs poor neurological outcome, are presented in Table 2. Selected variables were entered into simple binary logistic regression models for the prediction of mortality and poor neurological outcome. Results of the models are presented in Table 3. Mortality was found to be associated with the worst MSOFA score in the $\mathrm{CNICU}$, with each point increase in MSOFA resulting in 1.88 (1.33-2.96) times increase in chances of mortality. Lymphocyte percentage was also found to be associated with mortality, with each percentage point increase in lymphocyte ratio leading to a $13 \%$ reduction in chances of mortality. $\mathrm{LDH}_{\text {max }}$ level was also significantly associated with mortality albeit with smaller clinical significance, with an OR of 1.01 (1-1.02). Association with the presence of inotrope therapy was found to be statistically significant but a wide $95 \% \mathrm{Cl}$ [OR $=7.64$ (1.55-57.22), $p=0.021]$ precludes its consideration as a useful predictor (Table 3 ).

Similarly, a poor neurological outcome was found to be associated with the worst MSOFA score [OR $=1.99(1.36-3.33)$, $p=0.002], \mathrm{LDH}_{\max }$ levels, and inotrope therapy (Table 3).

\section{Discussion}

\section{Summary of Findings}

In this cohort of patients with combined neurological and COVID-19 illness, we observed high mortality of $59 \%$ and a poor outcome at discharge in $77 \%$ of the patients. Higher MSOFA scores and elevated LDH levels were associated with poor clinical outcomes (inhospital death or motor Glasgow Coma Scale <5). Additionally, lymphopenia was also a predictor of mortality. In this study, we observed that $75 \%$ of our patients were positive for COVID-19 at the time of admission itself, while $25 \%$ tested positive during their hospital stay. Most 
Critically Ill Neurological Patients with Concomitant COVID-19: Clinical Outcomes

Table 2: Descriptive variables in survivors vs non-survivors and good neurological outcome vs poor neurological outcome

\begin{tabular}{|c|c|c|c|c|}
\hline Variables & $\begin{array}{c}\text { Survivors } \\
(n=18)\end{array}$ & $\begin{array}{c}\text { Non-survivors } \\
(n=26)\end{array}$ & $\begin{array}{l}\text { Good outcome } \\
\quad(n=10)\end{array}$ & $\begin{array}{l}\text { Poor outcome } \\
\quad(n=34)\end{array}$ \\
\hline Age (years) & $45(34.5-58.75)$ & $46.5(38.5-58.75)$ & $45(35-53)$ & $46.5(37.25-60)$ \\
\hline M-GCS at admission & $5(5-6)$ & $5.5(5-6)$ & $6(5-6)$ & $5(4-6)$ \\
\hline \multicolumn{5}{|l|}{ Diagnosis } \\
\hline $\mathrm{TBI}$ & $5(27.8 \%)$ & $8(30.8 \%)$ & $3(30 \%)$ & $10(29.4 \%)$ \\
\hline Vascular & $7(38.9 \%)$ & $8(30.8 \%)$ & $3(30 \%)$ & $12(35.3 \%)$ \\
\hline Tumor & $2(11.1 \%)$ & $7(26.9 \%)$ & $1(10 \%)$ & $8(23.5 \%)$ \\
\hline Other & $4(22.2 \%)$ & $3(11.5 \%)$ & $3(30 \%)$ & $4(11.8 \%)$ \\
\hline CT score at admission & $2(0.5-6.5)$ & $4(0-10.75)$ & $3(2-6)$ & $3.5(0-10.25)$ \\
\hline Severe COVID-19 on chest imaging & $5(27.8 \%)$ & $12(48 \%)$ & $2(20 \%)$ & $15(45.5 \%)$ \\
\hline $\begin{array}{l}\text { Desaturation despite } \mathrm{O}_{2} \text { therapy } \\
\text { (mask or } \mathrm{MV}: \mathrm{SpO}_{2}<95 \% \text { ) }\end{array}$ & 7 (38.9\%) & 17 (65.4\%) & $3(30 \%)$ & 21 (61.8\%) \\
\hline $\begin{array}{l}\left.\text { (mask or IVIV; } \mathrm{SpO}_{2}<95 \%\right) \\
\text { Inotrope therapy }\end{array}$ & $11(61.1 \%)$ & $24(92.3 \%)$ & $\begin{array}{l}3(30 \%) \\
4(40 \%)\end{array}$ & $31(91.2 \%)$ \\
\hline MSOFA at ICU admission & $6(5-8)$ & $6.5(5-9)$ & $6(5-6.75)$ & $7(5-9)$ \\
\hline Worst MSOFA in CNICU & $7(5.25-9)$ & $10(9-11)$ & $6(5-6.75)$ & $10(9-11)$ \\
\hline Thrombocytopenia & $5(27.8 \%)$ & $11(42.3 \%)$ & $2(20 \%)$ & $14(41.2 \%)$ \\
\hline Lymphocyte count (\%) & $10.3(8.7-18.1)$ & $7.9(4.93-11.05)$ & $11.4(9.225-14.45)$ & $8.8(5.3-11.65)$ \\
\hline $\mathrm{LDH}_{\max }($ Units/L) & $455.5(328.25-498)$ & $592.5(513.0-687.5)$ & $354.5(292.25-447.75)$ & $586(484.5-661.25)$ \\
\hline $\mathrm{CRP}_{\max }(\mathrm{mg} / \mathrm{L})$ & $71.5(59.5-153)$ & $192(48-273)$ & $69(53.5-133)$ & $134(57.75-268.5)$ \\
\hline Ferritin $_{\max }(\mu \mathrm{g} / \mathrm{L})$ & $611(336.5-1485)$ & 1747 (674-2000) & $357(316-611)$ & $1747(773-2000)$ \\
\hline D-dimer ${ }_{\max }(\mathrm{ngFEU} / \mathrm{mL})$ & 2947 (1866-3573) & $5931(3615-10633)$ & $3573(3260-4014)$ & 4837 (1866-9233) \\
\hline Procalcitonin $(\mathrm{ng} / \mathrm{mL})$ & $0.35(0.13-1.5)$ & $1.28(0.52-5.07)$ & $0.22(0.10-0.89)$ & $1.28(0.33-3.04)$ \\
\hline Antiviral therapy & $4(23.5 \%)$ & $11(44 \%)$ & $1(11.1 \%)$ & $14(42.4 \%)$ \\
\hline Steroid therapy & $13(72.2 \%)$ & $21(84 \%)$ & $7(70 \%)$ & $27(81.8 \%)$ \\
\hline Anticoagulant therapy & $13(76.5 \%)$ & $17(65.4 \%)$ & $7(77.8 \%)$ & $23(67.6 \%)$ \\
\hline MV duration (days) & $18.5(9.25-24.5)$ & $14.5(4-26.75)$ & $13.5(4.25-20)$ & $17.5(5.75-27.75)$ \\
\hline CNICU stay (days) & $19.5(10.25-31.5)$ & $16(6.5-33)$ & $15.5(9-26)$ & $18.5(8.5-37.25)$ \\
\hline Hospital stay (days) & $34(18-45)$ & $20(8.25-48.75)$ & $33.5(19.5-37)$ & $24(11-50)$ \\
\hline
\end{tabular}

M-GCS, motor Glasgow coma scale; CT score, computed tomography score; MV, mechanical ventilation; $\mathrm{O}_{2}$, oxygen; $\mathrm{SpO}_{2}$, peripheral oxygen saturation; MSOFA, modified sequential organ failure assessment; CNICU, COVID-19 neuro-intensive care unit; $\mathrm{LDH}_{\text {max }}$ lactate dehydrogenase maximum levels; $\mathrm{CRP}_{\text {max }^{\prime}}$ C-reactive protein maximum levels; Ferritin max $^{\prime}$, ferritin maximum levels; D-dimer ${ }_{\text {max }}$ D-dimer maximum levels

Table 3: Results of binary logistic regression model for the prediction of mortality and poor neurological outcome

\begin{tabular}{|c|c|c|c|c|}
\hline \multirow[b]{2}{*}{ Variables } & \multicolumn{2}{|c|}{ Non-survivors } & \multicolumn{2}{|c|}{ Poor outcome } \\
\hline & OR $(95 \% C L)$ & pvalue & OR $(95 \% C L)$ & p value \\
\hline Age (years) & $1(0.96-1.04)$ & 0.961 & $1.01(0.96-1.06)$ & 0.788 \\
\hline Comorbidities & $0.55(0.14-2.03)$ & 0.370 & $0.5(0.09-2.3)$ & 0.387 \\
\hline M-GCS at hospital admission & $1.1(0.6-1.99)$ & 0.755 & $0.43(0.12-1.03)$ & 0.107 \\
\hline \multicolumn{5}{|l|}{ Diagnosis with reference to TBI } \\
\hline Vascular & $0.71(0.15-3.22)$ & 0.662 & $1.2(0.19-7.8)$ & 0.662 \\
\hline Tumor & $2.91(0.34-18.86)$ & 0.426 & $2.4(0.25-53.86)$ & 0.483 \\
\hline Other & $0.47(0.07-3.01)$ & 0.427 & $0.4(0.05-2.96)$ & 0.427 \\
\hline Severe COVID-19 on chest imaging & $2.4(0.68-9.38)$ & 0.185 & $3.33(0.7-24.38)$ & 0.164 \\
\hline Desaturation $\left(\mathrm{SpO}_{2}<95 \%\right)$ & $2.97(0.87-10.78)$ & 0.087 & $3.77(0.88-20)$ & 0.087 \\
\hline Inotrope therapy & $7.64(1.55-57.22)$ & 0.021 & $15.5(2.98-102.66)$ & 0.002 \\
\hline MSOFA at CNICU admission & $1.05(0.81-1.38)$ & 0.686 & $1.17(0.86-1.63)$ & 0.340 \\
\hline Worst MSOFA in CNICU & $1.88(1.33-2.96)$ & 0.002 & $1.99(1.36-3.33)$ & 0.002 \\
\hline Thrombocytopenia & $1.91(0.54-7.4)$ & 0.328 & $2.8(0.59-20.46)$ & 0.233 \\
\hline Lymphocyte count & $0.87(0.74-0.97)$ & 0.039 & $0.92(0.82-1)$ & 0.071 \\
\hline $\mathrm{LDH}_{\max }$ & $1.01(1-1.02)$ & 0.028 & $1.01(1-1.02)$ & 0.016 \\
\hline Ferritin $_{\max }$ & $1(1-1)$ & 0.193 & $1(1-1)$ & 0.056 \\
\hline Steroid therapy & $2.02(0.46-9.52)$ & 0.354 & $1.93(0.34-9.51)$ & 0.426 \\
\hline Anticoagulant therapy & $0.58(0.13-2.23)$ & 0.441 & $0.6(0.08-2.98)$ & 0.559 \\
\hline Antiviral therapy & $2.55(0.68-11.1)$ & 0.180 & $5.89(0.92-115.92)$ & 0.112 \\
\hline
\end{tabular}

M-GCS, motor Glasgow coma scale; $\mathrm{SpO}_{2}$, peripheral oxygen saturation; MSOFA, modified sequential organ failure assessment; CNICU, COVID-19 neuro-intensive care unit; $\mathrm{LDH}_{\text {max }}$ lactate dehydrogenase maximum levels; Ferritin max ferritin maximum levels 
of those who tested positive in the hospital were postoperative patients who underwent surgery for intracranial tumors. This study is, however, not able to inform if COVID-19 infection led to acute neurological manifestations, such as stroke in our patients, or COVID-19 was only a coexisting illness reportedly described in these population. ${ }^{4,5}$ It is also unclear from our study if our patients with acute neurological illnesses were more susceptible to COVID-19 infection as reported earlier. ${ }^{9}$

\section{Comparison with Previous Literature}

Severe COVID-19 infection can elicit cytokine storm with an increase in inflammatory markers and can affect multiple organs contributing to higher mortality. ${ }^{14}$ A meta-analysis on biomarkers and outcomes in COVID-19 identified lymphopenia, thrombocytopenia, elevated levels of LDH, CRP, D-dimer, and procalcitonin as markers of poor outcome. ${ }^{15}$ In our study, lymphopenia and $\mathrm{LDH}_{\max }$ levels were significantly associated with mortality, whereas $\mathrm{LDH}_{\max }$ was associated with poor outcomes. The median value of $\mathrm{LDH}_{\max }$ was 592.5 and $586 \mathrm{U} / \mathrm{L}$ in non-survivors and poor neurological outcome groups as against 455.5 and $354.5 \mathrm{U} / \mathrm{L}$ in survivors and good neurological outcome groups. Dong et al. also reported $\mathrm{LDH}$ as a predictor of inhospital mortality in severe and critically ill COVID-19 patients with significantly increased levels of LDH in the mortality group as compared to the survival group (559.5 vs $228 \mathrm{U} / \mathrm{L}){ }^{16}$ Lymphocyte percentage was lower among non-survivors and patients with poor neurological outcomes when compared with survivors and those with good outcomes (7.9 and $8.8 \%$ vs 10.3 and $11.4 \%$, respectively). Serum ferritin max $_{\text {levels were elevated }}$ (median values $1747 \mu \mathrm{g} / \mathrm{L}$ ) among non-survivors and those with poor neurological outcomes when compared to survivors $(611 \mu \mathrm{g} / \mathrm{L})$ and those with good neurological outcomes ( $357 \mu \mathrm{g} / \mathrm{L})$. The LDH, ferritin, D-dimer, and CRP levels were available in 59, 50, 36, and $52 \%$ of the patients. These were considerably elevated (>twice the upper levels) in non-survivors and those with poor neurological outcomes. Procalcitonin levels were available in $91 \%$ of the patients but they did not correlate with the outcomes.

Higher age, poor admission M-GCS, specific neurological diagnosis, or presence of comorbidities were not associated with adverse outcomes in our study. Previous studies have reported increased mortality in elderly (age $>60$ years) COVID-19 positive patients. ${ }^{17,18}$ Our patients were relatively younger (median age 46 years) with $30 \%$ having TBI pathology, and hence we probably did not observe an association between age and poor outcomes. Similarly, admission GCS and M-GCS predict outcomes in neurological patients. ${ }^{19,20}$ Many of our neurological patients with COVID-19 infection who had good M-GCS at admission developed clinical deterioration during their hospital stay, and therefore admission GCS was unrelated to outcomes. In our cohort, acute neurovascular pathologies (AIS, ICH, aSAH, and CVT) were the most common neurological diagnoses followed by TBI. Previous studies have also documented cerebrovascular disorders as the commonest neurological pathology coexisting with COVID-19 infection. 4,5,21,22 Also, COVID-19 patients with the neurological disease have higher mortality than those without COVID-19 disease. ${ }^{21}$ However, there are no studies evaluating outcomes in COVID-19 patients with TBI.

Severe neurological manifestation is more common in patients with severe COVID-19 infection and similarly, the risk of severe COVID-19 increases in patients with neurological disorders. ${ }^{9}$ Severe COVID-19 is considered when the patient has $>50 \%$ lung infiltrates on chest imaging. ${ }^{23}$ In our cohort, severe lung involvement on the chest imaging was observed in 17 (39.5\%) patients. However, it was not associated with increased mortality $(p=0.185)$ or neurological outcome $(p=0.164)$.

The impact of COVID-19 infection on neurological outcome in our cohort appears to be uncertain and difficult to comment upon in the absence of the non-COVID-19 comparator arm. The severity of pulmonary involvement from COVID-19 as evidenced by imaging findings was low to affect the clinical outcome. However, inflammatory markers of COVID-19 were significantly elevated and systemic inflammation could have affected the overall patient outcome. The cytokine storm associated with COVID-19 infection is known to contribute to multi-organ failure and poor outcomes. ${ }^{14}$ The SOFA score informs about the organ function over time and is useful in predicting outcomes in ICU patients. The SOFA score has been found to accurately predict outcomes in critically ill neurological patients ${ }^{24}$ and also in patients with severe COVID-19 illness. ${ }^{21}$ The MSOFA score considers the $\mathrm{SpO}_{2} / \mathrm{FiO}_{2}$ ratio instead of the $\mathrm{PaO}_{2} / \mathrm{FiO}_{2}$ ratio, does not require laboratory values of bilirubin and platelets, and predicts mortality as similar to the SOFA score. ${ }^{12}$ In our cohort of critically ill neurological patients with COVID-19, we observed that the worst MSOFA score predicted both the mortality (10 vs 7 for non-survivors vs survivors) and the neurological outcome (10 vs 6 for poor vs good neurological outcome) similar to that reported in the non-COVID-19 population. ${ }^{12}$ The worst MSOFA score was observed on day two (median) of CNICU admission, and an increase in the score by 1 was found to increase the odds of death and poor neurological outcome by 1.88 and 1.99 times, respectively. Our findings of the worst MSOFA score, elevated LDH levels, and lymphopenia predicting the mortality are similar to that reported by Benussi et al. ${ }^{21}$ who found qSOFA score, thrombocytopenia, and higher LDH levels at admission to be predictive of inhospital mortality in COVID-19 patients.

The mortality in critically ill neurological patients is reported between 32 and $56.6 \%$ and depends on the underlying pathology, severity of disease, age, presence of comorbidities, and requirement of MV among others. ${ }^{19,25}$ Similarly, mortality in patients with severe COVID-19 requiring ICU care varies from 29 to $61.5 \%$ and is due to the limited knowledge in managing these patients in the early days, regional variation, strain types, and varied duration of follow-up. ${ }^{17,18}$ Advanced age, associated comorbidities, need for MV, and multiorgan failure contributed to higher mortality. In COVID-19 patients with neurological disease, the inhospital mortality was significantly higher in COVID-19 than non-COVID-19 patients ( $n=21 / 56,37.5 \%$ vs $n=5 / 117,4.3 \%) .{ }^{21}$ In another study from Italy, including patients presenting to the emergency department with neurological symptoms, the mortality was again higher in COVID-19 compared to non-COVID-19 patients (29.7 vs $3.1 \%){ }^{5}$ A recent study noted a very low incidence (1.4\%) of simultaneous COVID-19 infection in critically ill neurological/neurosurgical patients probably from under-reporting due to varied testing criteria. They observed similar mortality during and before the COVID-19 pandemic in critically ill neurological patients (12.2\% in 2020 vs $12.4 \%$ in 2019$).{ }^{22}$

Steroids, anticoagulants, and antivirals were commonly used in our country for the management of COVID-19 patients on MV in the ICU. These drugs did not affect the outcome in our cohort. The living project suggested a mortality benefit with the use of dexamethasone and remdesivir in COVID-19 patients; however, the evidence was low to very low. ${ }^{26}$ Contradictory evidence also exists, which refutes the benefit of remdesivir and favipiravir and suggests cautious use of dexamethasone to only critically ill 
COVID-19 patients. ${ }^{27}$ Prophylactic anticoagulation is recommended for all hospitalized patients with COVID-19 unless the risk of bleeding is higher than that of thrombosis. ${ }^{28}$ Therapeutic anticoagulation, while decreasing the mortality and need for MV, increased the bleeding risk in patients with severe COVID-19 disease. ${ }^{29}$

\section{Strengths and Limitations}

This is the first study from India describing the clinical characteristics and reporting the predictors of outcomes in exclusive neurological patients with concomitant COVID-19 infection requiring MV in the ICU. The limitations of our study include the small sample size from a single center, retrospective nature of the study resulting in incomplete data regarding imaging and laboratory markers, and the absence of non-COVID-19 comparator arm to establish the contribution of COVID-19 per se on neurological outcomes.

\section{Conclusions}

In our study, neurological patients with concomitant COVID-19 infection had high mortality and poor outcomes. Inflammatory markers of COVID-19 were significantly elevated in these patients, suggesting the role of systemic inflammation on outcomes. Predictors of mortality and poor outcome were higher MSOFA scores and elevated LDH levels. Additionally, lymphopenia was associated with mortality. Studies with a larger sample size and having comparator arm of non-COVID-19 neurological patients are needed for a better understanding of the impact of COVID-19 infection on neurological outcomes.

\section{Author's Contribution}

Rohini M Surve and Kamath Sriganesh conceptualized the work; data acquisition was done by Rohini M Surve, Rajeeb Kumar Mishra, Soumya Ranjan Malla and Mahendranath Musunuru. The analysis of the manuscript and interpretation of the data was carried out by Rohini M Surve, Rajeeb Kumar Mishra, Kamath Sriganesh, Dhritiman Chakrabarti and Karthik Kulanthaivelu, and Dhritiman Chakrabarti analyzed the data. Rohini M Surve drafted the manuscript; Rajeeb Kumar Mishra, Kamath Sriganesh, Dhritiman Chakrabarti, and Karthik Kulanthaivelu reviewed the manuscript, and finally, Rohini M Surve and Kamath Sriganesh revised the manuscript.

\section{ORCID}

Rohini M Surve ำ https://orcid.org/0000-0002-5740-7122 Rajeeb KMishra 이ths://orcid.org/0000-0003-4830-0347 Soumya R Malla @ https://orcid.org/0000-0002-5541-1582 Sriganesh Kamath ㄴ) https://orcid.org/0000-0003-2355-0403 Dhritiman R Chakrabarti @ https://orcid.org/0000-0003-4804-5403 Karthik Kulanthaivelu (1) https://orcid.org/0000-0002-1585-8769 Mahendranath Musunuru (0 https://orcid.org/0000-0002-6155-2234

\section{References}

1. Lai CC, Shih TP, Ko WC, Tang HJ, Hsueh PR. Severe acute respiratory syndrome coronavirus 2 (SARS-CoV-2) and coronavirus disease-2019 (COVID-19): the epidemic and the challenges. Int J Antimicrob Agents 2020;55(3):105924. DOI: 10.1016/j.ijantimicag.2020.105924.

2. Johnson KD, Harris C, Cain JK, Hummer C, Goyal H, Perisetti A. Pulmonary and extra-pulmonary clinical manifestations of COVID-19. Front Med 2020;7:526. DOI: 10.3389/fmed.2020.00526.

3. Paterson RW, Brown RL, Benjamin L, Nortley R, Wiethoff S, Bharucha T, et al. The emerging spectrum of COVID-19 neurology: clinical, radiological and laboratory findings. Brain 2020;143(10):3104-3120. DOI: 10.1093/brain/awaa240.

4. Cagnazzo F, Arquizan C, Derraz I, Dargazanli C, Lefevre PH, Riquelme C, et al. Neurological manifestations of patients infected with the SARS-CoV-2: a systematic review of the literature. J Neurol 2021;268(8):2656-2665. DOI: 10.1007/s00415-020-10285-9.

5. Pilotto A, Benussi A, Libri I, Masciocchi S, Poli L, Premi E, et al. COVID-19 impact on consecutive neurological patients admitted to the emergency department. J Neurol Neurosurg Psychiatry 2021;92(2):218-220. DOI: 10.1136/jnnp-2020-323929.

6. Mao L, Jin H, Wang M, Hu Y, Chen S, He Q, et al. Neurologic manifestations of hospitalized patients with coronavirus disease 2019 in Wuhan, China. JAMA Neurol 2020;77(6):683-690. DOI: 10.1001/ jamaneurol.2020.1127.

7. Harapan BN, Yoo HJ. Neurological symptoms, manifestations, and complications associated with severe acute respiratory syndrome coronavirus 2 (SARS-CoV-2) and coronavirus disease 19 (COVID-19). J Neurol 2021;268(9):3059-3071. DOI: 10.1007/s00415-021-10406-y.

8. Zirpe K, Dixit S, Kulkarni AP, Sapra H, Kakkar G, Gupta R, et al. Pathophysiological mechanisms and neurological manifestations in COVID-19. Indian J Crit Care Med 2020;24(10):975-980. DOI: 10.5005/ jp-journals-10071-23592.

9. Honardoost M, Janani L, Aghili R, Emami Z, Khamseh ME. The association between presence of comorbidities and COVID-19 severity: a systematic review and meta-analysis. Cerebrovasc Dis 2021;50(2):132-140. DOI: 10.1159/000513288.

10. Borghesi A, Zigliani A, Golemi S, Carapella N, Maculotti P, Farina D, et al. Chest X-ray severity index as a predictor of in-hospital mortality in coronavirus disease 2019: a study of 302 patients from Italy. Int J Infect Dis 2020;96:291-293. DOI: 10.1016/j.jijid.2020.05.021.

11. Yang R, Li X, Liu H, Zhen Y, Zhang X, Xiong Q, et al. Chest CT severity score: an imaging tool for assessing severe COVID-19. Radiol Cardiothorac Imag 2020;2(2):e200047. DOI: 10.1148/ ryct.2020200047.

12. Grissom CK, Brown SM, Kuttler KG, Boltax JP, Jones J, Jephson AR, et al. A modified sequential organ failure assessment score for critical care triage. Dis Med Publ Health Prep 2010;4(4):277-284. DOI: 10.1001/ dmp.2010.40.

13. Vanamoorthy P, Singh GP, Bidkar PU, Mitra R, Sriganesh K, Chavali S, et al. The Neurocritical Care Society of India (NCSI) and the Indian Society of Neuroanaesthesiology and Critical Care (ISNACC) joint position statement and advisory on the practice of neurocritical care during the COVID-19 pandemic. J Neuroanaesth Crit Care 2020;7(03):128-139. DOI: 10.1055/s-0040-1714648.

14. Mokhtari T, Hassani F, Ghaffari N, Ebrahimi B, Yarahmadi A, Hassanzadeh G. COVID-19 and multi-organ failure: a narrative review on potential mechanisms. J Mol Histol 2020;51(6):613-628. DOI: 10.1007/s10735-020-09915-3.

15. Malik P, Patel U, Mehta D, Patel N, Kelkar R, Akrmah M, et al. Biomarkers and outcomes of COVID-19 hospitalisations: systematic review and meta-analysis. BMJ Evid Based Med 2021;26(3):107-108. DOI: 10.1136/ bmjebm-2020-111536.

16. Dong X, Sun L, Li Y. Prognostic value of lactate dehydrogenase for in-hospital mortality in severe and critically ill patients with COVID-19. Int J Med Sci 2020;17(14):2225-2231. DOI: 10.7150/ijms.47604.

17. Thomson RJ, Hunter J, Dutton J, Schneider J, Khosravi M, Casement A, et al. Clinical characteristics and outcomes of critically ill patients with COVID-19 admitted to an intensive care unit in London: a prospective observational cohort study. PLoS One 2020;15(12):e0243710. DOI: 10.1371/journal.pone.0243710.

18. Xu J, Yang X, Yang L, Zou X, Wang Y, Wu Y, et al. Clinical course and predictors of 60 -day mortality in 239 critically ill patients with COVID-19: a multicenter retrospective study from Wuhan, China. Crit Care 2020;24(1):394. DOI: 10.1186/s13054-020-03098-9.

19. Kramer AH, Zygun DA. Declining mortality in neurocritical care patients: a cohort study in Southern Alberta over eleven years. Can J Anesth 2013;60(10):966-975. DOI: 10.1007/s12630-013-0001-0. 
20. Ting HW, Chen MS, Hsieh YC, Chan CL. Good mortality prediction by Glasgow Coma Scale for neurosurgical patients. J Chin Med Assoc 2010;73(3):139-143. DOI: 10.1016/S1726-4901(10)70028-9.

21. Benussi A, Pilotto A, Premi E, Libri I, Giunta M, Agosti C, et al. Clinical characteristics and outcomes of inpatients with neurologic disease and COVID-19 in Brescia, Lombardy, Italy. Neurology 2020;95(7): e910-e920. DOI: 10.1212/WNL.0000000000009848.

22. Shah VA, Nalleballe K, Onteddu SR. Critically ill neurologic patients during the COVID-19 pandemic: a short communication. Brain Behav Immun Health 2021;12:100207. DOI: 10.1016/j.bbih.2021.100207.

23. National Institutes of Health. Clinical spectrum of SARS-CoV-2 infection. 2020. Available from: https://www.covid19treatmentguidelines.nih gov/overview/clinical-spectrum/.

24. Abrahão LR, De Marco FVC, Maciel FMB, Giudicissi M, Bianco ACM, Mora MA. Application of SOFA score to neurological patients admitted to intensive care unit. Crit Care 2002;6(Suppl. 1):P237. DOI: $10.1186 /$ cc1704.

25. Popat C, Ruthirago D, Shehabeldin M, Yang S, Nugent K. Outcomes in patients with acute stroke requiring mechanical ventilation: predictors of mortality and successful extubation. Am J Med Sci 2018;356(1):3-9. DOI: 10.1016/j.amjms.2018.03.013.
26. Juul S, Nielsen EE, Feinberg J, Siddiqui F, Jørgensen CK, Barot E, et al. Interventions for treatment of COVID-19: a living systematic review with meta-analyses and trial sequential analyses (The LIVING Project) [published correction appears in PLoS Med 2020 Dec 29;17(12):e1003517]. PLoS Med 2020;17(9):e1003293. DOI: 10.1371/journal.pmed.1003293.

27. Kelleni MT. Tocilizumab, remdesivir, favipiravir, and dexamethasone repurposed for COVID-19: a comprehensive clinical and pharmacovigilant reassessment. SN Compr Clin Med 2021;1-5. DOI: 10.1007/ s42399-021-00824-4.

28. Thachil J, Tang N, Gando S, Falanga A, Cattaneo M, Levi M, et al. ISTH interim guidance on recognition and management of coagulopathy in COVID-19. J Thromb Haemost 2020;18(5):1023-1026. DOI: 10.1111/ jth.14810.

29. Jiménez-Soto $R$, Aguilar-Soto $M$, Rodríguez-Toledo $C A$, CamiroZúñiga A, Demichelis R; ARMII Study Group. The impact of different prophylactic anticoagulation doses on the outcomes of patients with COVID-19. Thromb Res 2021;202:14-16. DOI: 10.1016/j. thromres.2021.02.031. 